\title{
Osteoporosis-pseudoglioma syndrome: clinical, morphological, and biochemical studies
}

\author{
HANNU SOMER*, AARNO PALOTIE†, MIRJA SOMER , \\ VEIJO HOIKKA $\S$, AND LEENA PELTONEN† \\ From *the Department of Neurology, University of Helsinki; the Collagen Research Unit, University of \\ Oulu; ¥the Finnish Population and Family Welfare Federation, Väestöliitto, Helsinki; and §the Orthopaedic \\ Hospital of the Invalid Foundation, Helsinki, Finland.
}

SUMMARY We report a sibship of a sister and brother with osteoporosis-pseudoglioma syndrome. Several other family members became blind or showed signs of bone involvement. There was considerable consanguinity in the pedigree. The proband was small in size and had prominent skeletal deformities and clinical muscle weakness. These features were not present in her brother, suggesting clinical variability. Mental function was normal in both. Bone histology showed osteopenia. Several biochemical events of procollagen biosynthesis were analysed in fibroblast cultures, but no significant abnormalities compared to control fibroblast cultures were detected.

Osteoporosis-pseudoglioma syndrome is a rare genetic disorder with autosomal recessive transmission. Characteristic findings are generalised osteoporosis and blindness, which is usually due to retinal detachment. ${ }^{1}$ Other manifestations, such as muscular hypotonia, hyperextensible joints, and mental retardation, are present to a variable extent. Frontali et $a l^{2}$ reviewed the published reports and found 21 cases, mainly from the Mediterranean area. Seven other cases published separately ${ }^{34}$ are likely to represent the same entity.

The disorder is presumed to be an inherited connective tissue disease although very little is known of the underlying pathology. We present two further cases and the results of morphological and biochemical studies.

\section{Case reports}

\section{CASE 1}

The proband (V.2) and her brother (V.5) are products of a highly consanguineous marriage (fig 1). Their ancestors can be traced back for more than two centuries and they all come from a small rural village. At least five consanguineous marriages are detectable. Several family members became blind at varying ages and many members are reported to have suffered from some kind of bone involvement,

Received for publication 25 March 1987

Revised version accepted for publication 14 September 1987. but only members of the last generation have been studied with adequate methods.

The proband was born preterm, slightly asphyxiated because the umbilical cord was around the neck. She recovered immediately, however, and neonatal development was normal. She sat at the age of one year and spoke words at 18 months. Motor development was delayed. She learned to get up from the floor and to stand with support between the ages of five and eight, but she never learned to walk unsupported and has been using a wheelchair for two decades. At the age of five vision gradually started to deteriorate in the left eye and the eye was removed; the diagnosis was retrolental fibroplasia. At the age of eight the vision also started to deteriorate in the right eye. Physical examination revealed clouding of the cornea and the lens, as well as nystagmus. There was generalised muscle weakness and hypotonia. She was unable to raise her head from bed and could stand with support for short periods only. She had a prominent scoliosis in the thoracic and lumbar spine. $X$ rays showed generalised osteoporosis. Vision deteriorated gradually and at the age of 10 she was completely blind. She was treated at home and was admitted to a school for the blind when she was 29 years old. There she was a good student, and she is at the moment continuing her studies at university. She had one bone fracture at the age of 32 .

Further examinations were carried out at the age of 36. Physical examination showed a blind woman 
III
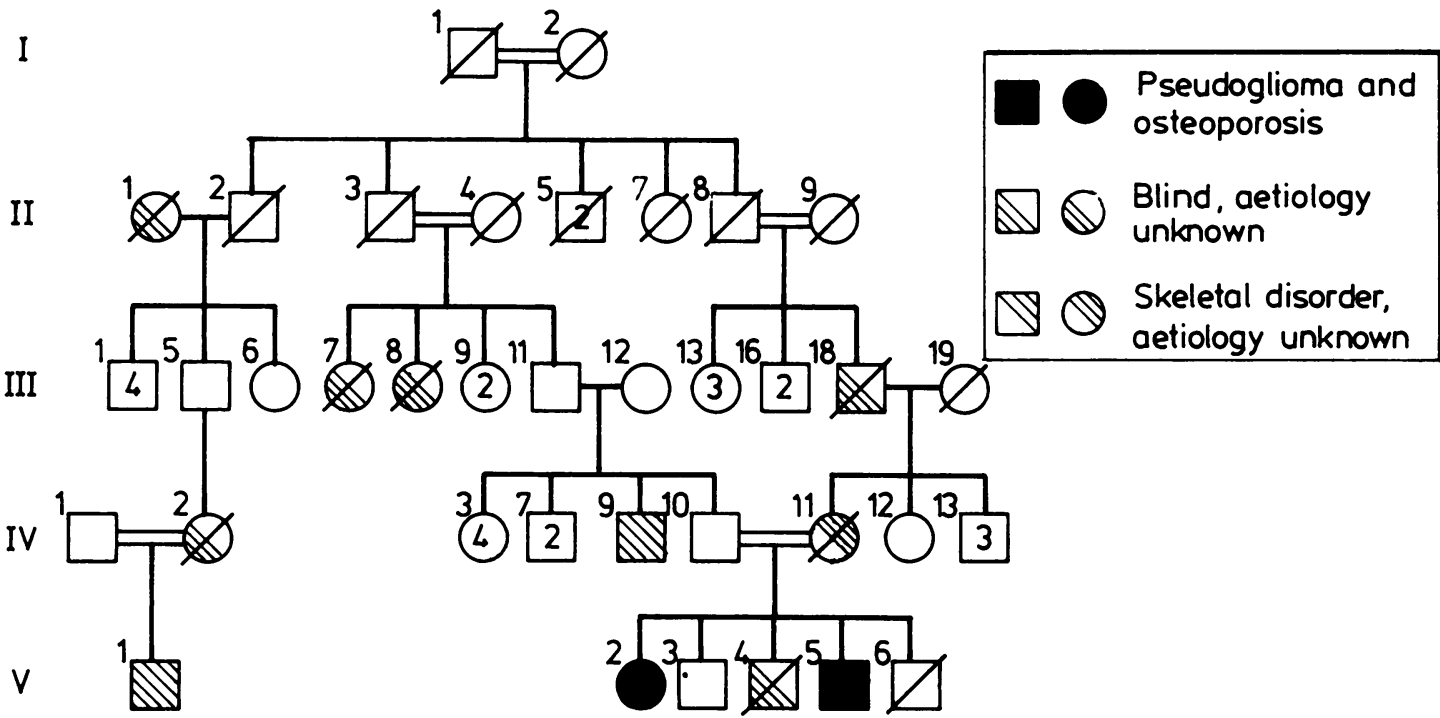

FIG 1 Pedigree of the family. II.I blind in middle age. III.7 blind at age four. III.8 poor vision. III.18 blind at age 36. IV.2 diabetes, poor vision, skeletal weakness. IV.9 untreated Legg-Perthes-Calve disease, right eye blind at age 60. IV.II thoracic kyphosis, wedge shaped vertebrae, and mild osteoporosis noted at age 70. V.I one eye almost blind, skeletal abnormality. V.4 blind from early age, died accidentally at age 21.

with abnormal craniofacial features (fig $2 \mathrm{a}$ and $\mathrm{b}$ ). She had a broad face with a short philtrum and a prominent mouth region. The ears were located somewhat lower than usual and were tilted posteriorly. The posterior side of the skull was flattened. She also had micrognathia and a depressed bridge of the nose. OFC was $53.5 \mathrm{~cm}$.

She was of short stature $(147 \mathrm{~cm})$. The upper segment/lower segment ratio was $0 \cdot 81$. Her neck was short. The thoracic spine showed a prominent kyphosis and scoliosis. The extremities were disproportionately long with a span of $164 \mathrm{~cm}$ in the upper extremities. The fingers were long and their joints were hyperextensible, whereas the feet were short. The knees were fixed in a valgus position and the feet in an equinovarus position. She had no contractures.

Intellectual function was normal. She had a generalised, predominantly proximal muscle weakness and hypotonia, which had remained relatively unchanged since the age of eight. Tendon reflexes were normal except for brisk patella reflexes. Ophthalmological examination showed laterally sparse eyebrows. The left eye had been replaced with a prosthesis and the right eye showed microphthalmia and corneal clouding. She was entirely blind with no response either on ERG or VEP.

Bone $x$ rays showed generalised osteoporosis and there were some osteoporotic cysts in the metatarsaT bones (fig 3a). The thoracic and lumbar spine showed a prominent scoliosis (fig 4a). The cervical spine contained some slight anomalies and osteoporosis, but no sign of medullary compression. Computerised tomography of the brain showed mild, predominantly central brain atrophy. Computerised tomography of the orbits showed atrophy of the bulbi with some calcification in the frontal region.

EEG showed mild, non-specific changes with no spikes or sharp waves and EMG showed increased amounts of polyphasic potentials of short duration, especially in the proximal muscles of the upper extremities. ECG and echocardiography were normal.

CASE 2

The second patient, the proband's younger brother 0 (V.5), was born at term after an uneventful $\mathcal{O}$ pregnancy. His left eye was apparently blind from N birth. The right eye had some vision but became blind in the space of one day at the age of eight. 0 Developmental milestones were otherwise normal. $\frac{D}{D}$ He entered a school for blind children and subse- $\stackrel{\oplus}{\rightarrow}$ quently, with special arrangements, studied 7 mathematics at university. His intellectual capacity appeared to be excellent and he has collaborated in $\stackrel{\odot}{\Phi}$ the development of a special device for the blind. At $\stackrel{\mathbb{Q}}{\mathscr{Q}}$ 


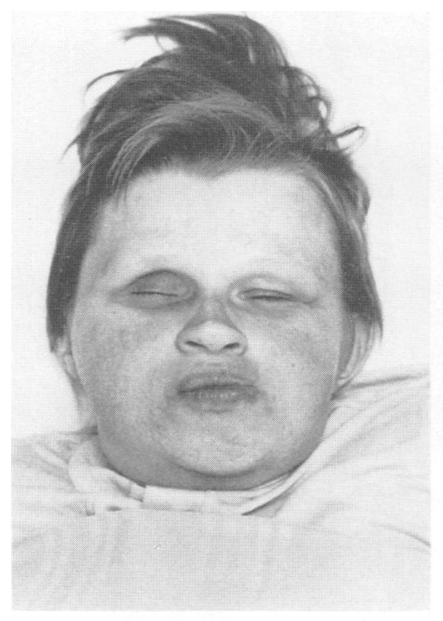

(a)

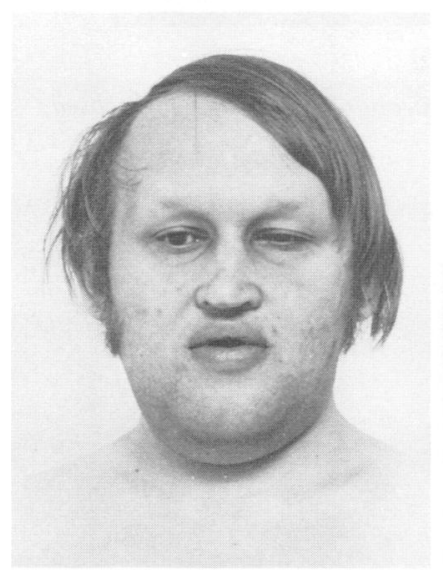

(c)

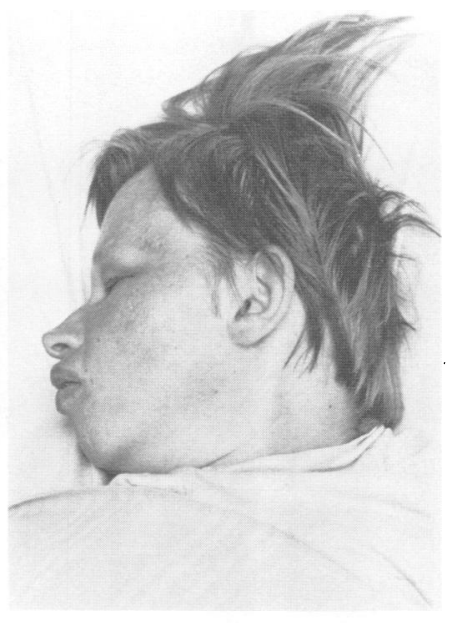

(b)

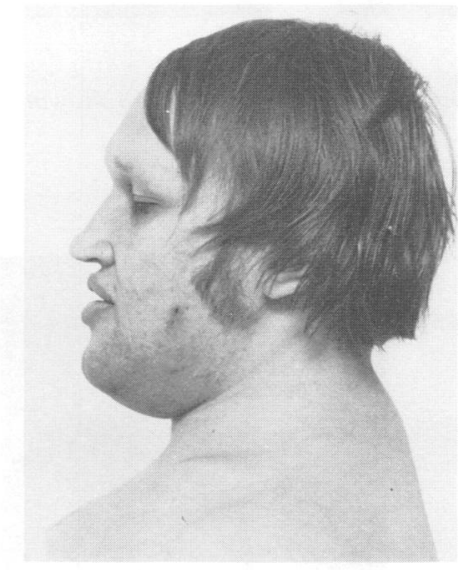

(d)
FIG 2 Facial appearance of the proband $(a, b)$ and her affected brother $(c, d)$. the age of 28 he had an epileptic seizure after substantial consumption of alcohol on the previous evening. On recovering consciousness he complained of back pain. $X$ rays of the spine showed compression fractures in four thoracic vertebrae and generalised osteoporosis.

An extensive medical examination was carried out at the age of 30 . The facial appearance was abnormal. The forehead and the eyebrows were prominent and the philtrum was short. The nose was broad with hypoplastic alae (fig $2 \mathrm{c}$ and d). He was of normal size $(169 \mathrm{~cm})$, but the extremities were disproportionately long with a span of $192 \mathrm{~cm}$ in the upper extremities and an upper/lower segment ratio of 0.94 . His OFC was $57 \mathrm{~cm}$ and weight was $80 \mathrm{~kg}$.

Both eyes were completely blind. Band kerato- pathy was present in the cornea in both eyes. The eye bulbs were of reduced size and showed calcification on computerised tomography of the orbits (fig 5). Bone $x$ rays showed generalised osteoporosis (fig $3 b)$, old compression fractures in the thoracic vertebrae, and a mild scoliosis (fig 4b). His muscle strength and muscle bulk were both normal. EEG and EMG gave normal results.

\section{LA BORATORY INVESTIGATIONS}

Routine blood and urinary analyses were normal in both patients. Other laboratory examinations included serum concentrations and daily urinary excretion of calcium and phosphorus, serum alkaline phosphatase, serum parathyroid hormone and calcitonin measurements, serum concentration and 


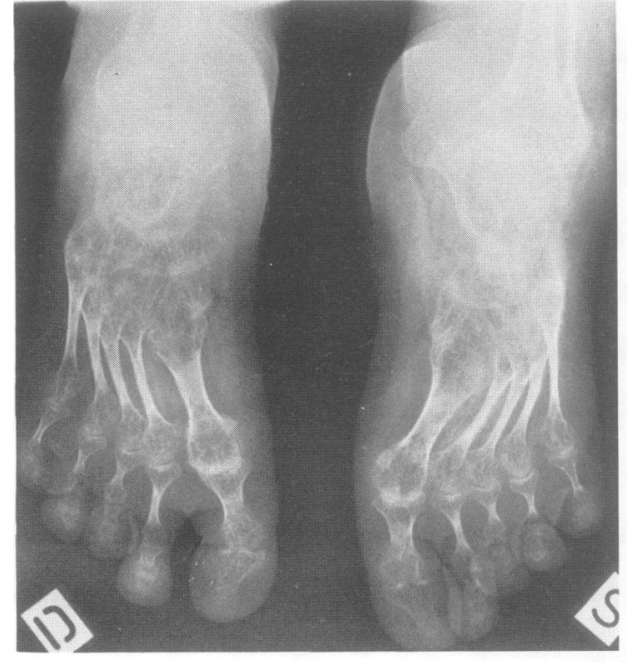

(a)

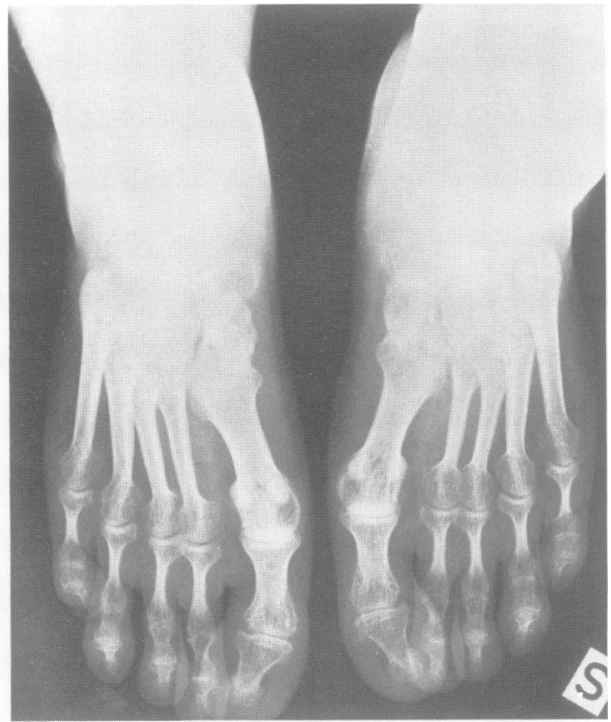

(b)

FIG $3 X$ rays of the metatarsal bones of the proband (a) and her brother (b) showing osteoporotic cysts and generalised osteoporosis.

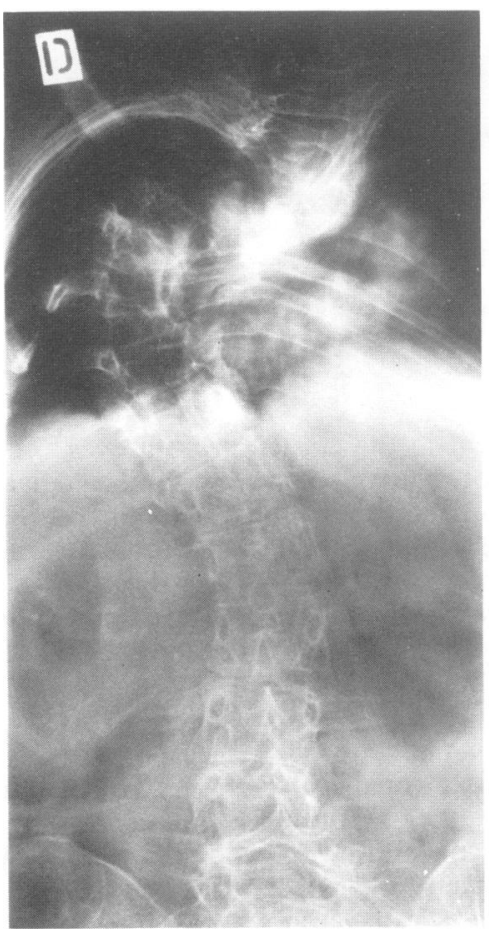

(a)

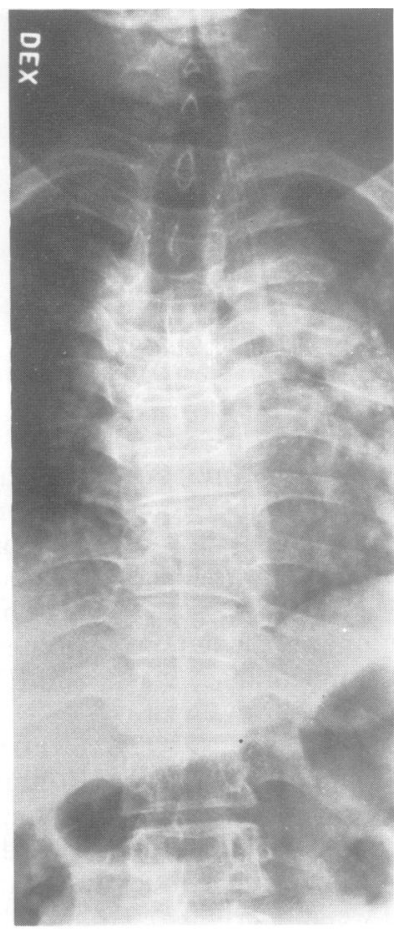

(b)
FIG $4 \quad X$ rays of the spine showing profound scoliosis and osteoporosis in the proband (a) and osteoporosis and old compression fractures in her brother $(b)$. 


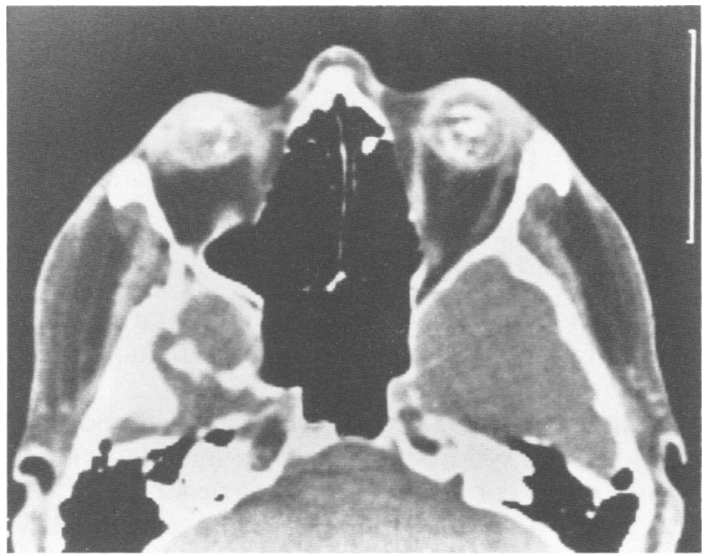

FIG $5 C T$ scan of the orbits (V.5) showing atrophy and calcification of the bulbi.

urinary excretion of hydroxyproline, measurements of $24,25(\mathrm{OH})_{2}-\mathrm{D}_{3}$ and $1,25-(\mathrm{OH})_{2}-\mathrm{D}_{3}$ levels in plasma, serum ceruloplasmin and copper determinations, urinary excretion of cyclic AMP, analysis of urinary amino acids and measurements of glycosaminoglycans in the urine. All these studies were performed in both patients on several occasions, but they all gave normal results.

\section{Material and methods}

MUSCLE BIOPSY

A muscle biopsy was taken from the vastus lateralis muscle from both patients and processed for routine light microscopic examination.

BONE BIOPSY

Biopsies were taken from the iliac crest from both patients. Histological analysis of the undecalcified cancellous bone included measurements of the amount of trabecular bone, the amount of osteoid, and the amount of trabecular resorption surfaces. ${ }^{5}$
TISSUE CULTURE STUDIES ON COLLAGEN

META B O LIS M

Skin fibroblast cultures were established from skin biopsies and grown by routine methods as described previously. ${ }^{6}$ Prolyl 4-hydroxylase (PH), lysyl hydroxylase ( $\mathrm{LH})$, hydroxylysyl galactosyl transferase (HGT), galactosylhydroxylysyl glucosyltransferase (GGT), and lysyl oxidase (LO) activities were analysed from cultured skin fibroblasts as described previously. ${ }^{67}$ To quantify the secreted collagenous protein, the fibroblast cultures were labelled with ${ }^{14} \mathrm{C}$-proline for 24 hours and the ${ }^{14} \mathrm{C}$-hydroxyproline content was analysed from the medium by the method of Juva and Prockop, ${ }^{8}$ as described in Peltonen et al. ${ }^{6}$ The labelling of procollagen chains with ${ }^{14} \mathrm{C}$-proline was performed essentially as described by Deak et al. ${ }^{9}$ To prevent the post-translational modifications, occasionally $1 \mathrm{mmol} / 1 \alpha^{\prime}, \mathrm{a}^{\prime}$ dipyridyl was added. The procollagen chains were separated on 4 to $8 \%$ gradient SDS-polyacrylamide gel electrophoresis and visualised by fluorography. ${ }^{10}$

\section{Results}

\section{MUSCLE BIOPSY}

Histological examination of the biopsy obtained from the proband (V.2) showed generalised muscle fibre atrophy, but no sign of myopathy or denervation. The microscopic picture was compatible with disuse atrophy. The muscle biopsy obtained from the second patient (V.5) was normal.

\section{BONE BIOSPY}

The amount of cancellous bone was decreased in both patients. The proband had a slightly increased amount of osteoid. The amount of resorption surfaces was within normal limits in both patients.

\section{TISSUE CULTURE STUDIES}

The activities of the intracellular enzymes $(\mathrm{PH}, \mathrm{LH}$, HGT, GGT) catalysing the various steps in procollagen biosynthesis, as well as the extracellularly acting lysyloxidase, were no different from control

TABLE 1 Enzyme activities of procollagen biosynthesis.

\begin{tabular}{|c|c|c|}
\hline & Patients & Controls \\
\hline Prolyl-4-hydroxylase (PH) & $\begin{array}{l}127 \times 10^{3} \mathrm{cpm} / 10^{6} \text { cells } \\
\left(\text { range } 124-131 \mathrm{cpm} / 10^{6}\right)\end{array}$ & $\begin{array}{l}190 \times 10^{3} \mathrm{cpm} / 10^{6} \text { cells } \\
(\mathrm{SD} 66)\end{array}$ \\
\hline Procollagen lysylhydroxylase (LH) & $\begin{array}{l}43 \cdot 7 \times 10^{3} \mathrm{cpm} / 10^{6} \text { cells } \\
(\text { range } 37 \cdot 5-49 \cdot 8)\end{array}$ & $\begin{array}{l}48.2 \times 10^{3} \mathrm{cpm} / 10^{6} \text { cells } \\
\quad(\mathrm{SD} 21 \cdot 4)\end{array}$ \\
\hline Hydroxylysyl galactolysyl transferase (HGT) & $\begin{array}{l}85.7 \times 10^{3} \mathrm{cpm} / 10^{6} \text { cells } \\
(\text { range } 79.6-91.9)\end{array}$ & $\begin{array}{l}111 \times 10^{3} \mathrm{cpm} / 10^{6} \text { cells } \\
(\mathrm{SD} 45)\end{array}$ \\
\hline Galactosyl hydroxylysyl glucosyl transferase (GGT) & $\begin{array}{l}24 \cdot 2 \times 10^{3} \mathrm{cpm} / 10^{6} \text { cells } \\
(\text { range } 22 \cdot 2-26 \cdot 4)\end{array}$ & $\begin{array}{l}37 \times 10^{3} \mathrm{cpm} / 10^{6} \text { cells } \\
(\mathrm{SD} 14 \cdot 3)\end{array}$ \\
\hline Lysyloxidase (LO) & $\begin{array}{l}2790 \mathrm{cpm} / 10^{6} \text { cells } \\
\text { (range } 2610-2920)\end{array}$ & $\begin{array}{l}22(0) \mathrm{cpm} / 10^{6} \text { cells } \\
(\mathrm{SD} 549)\end{array}$ \\
\hline
\end{tabular}


TABLE $2{ }^{14}$ C-hydroxyproline production of cultured osteoporosis-pseudoglioma fibroblasts.

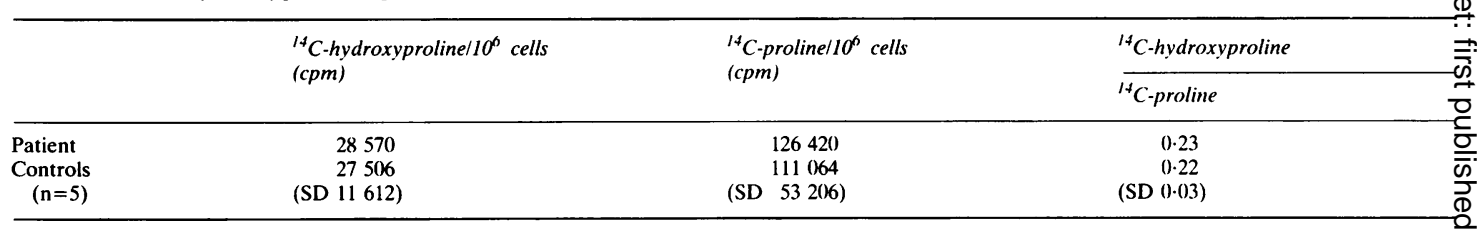

values (table 1). Excretion of ${ }^{14} \mathrm{C}$-hydroxyproline was also normal (table 2).

No major differences could be detected in the electrophoretic mobility of the intracellular type I procollagen chains (two hour labelling, data not shown) and, also, the secreted ${ }^{14} \mathrm{C}$-proline labelled $\alpha 1(\mathrm{I})$ and $\alpha 2(\mathrm{I})$ (24 hour labelling) migrated the same way in both the patients' and the control culture media (data not shown).

\section{Discussion}

The combination of juvenile osteoporosis and vitreoretinal dysplasia or phthisis bulbi is typical of the osteoporosis-pseudoglioma syndrome. ${ }^{11}$ The syndrome is thought to be inherited in an autosomal recessive fashion. Some findings in this pedigree may look exceptional, although they are not actually contrary to this mode of inheritance. Several family members became blind at various stages of their lives, but unfortunately it is not possible to diagnose the cause of their blindness in retrospect. Some of them may have had the same syndrome, as they became blind suddenly at a young age and occasionally had simultaneous skeletal involvement. The pedigree data are not incompatible with autosomal recessive inheritance because of the exceptionally high consanguinity rate present in the pedigree.

Although both patients showed the cardinal features of the syndrome, the manifestations differed to some extent. The proband was small in size and had pronounced skeletal deformities and clinical muscle weakness, whereas her brother was of normal size and had normal muscle strength. His juvenile osteoporosis became clinically apparent only when he had a compression fracture of the thoracic vertebrae because of an epileptic seizure. The sibs thus illustrate the variability of clinical features. In some cases the skeletal abnormalities may apparently remain unnoticed for a long period of time.

Mental retardation was considered to be a common feature in the syndrome for some time,${ }^{11}$ but in a recent review ${ }^{2}$ only seven out of the 20 cases were found to be retarded. Since our two cases were exceptionally bright students, and none of the seven other cases published separately ${ }^{34}$ was retarded, it seems fair to conclude that mental retardation is $\vec{\circ}$ actually rare in the osteoporosis-pseudoglioma syndrome.

Various authors have suggested that osteoporosis $\frac{2}{7}$ pseudoglioma syndrome should be included among the inherited connective tissue disorders, ${ }^{1}{ }^{2} 12$ butîn little is known about the underlying abnormality. $\infty$ Bone pathology has been described in one paper ${ }^{13} \mathrm{cr}$ and in one recent abstract ${ }^{4}$ only. Bone histology appears to distinguish the syndrome from osteo-을 genesis imperfecta, ${ }^{4}$ but apart from this offers fewclues to the basic abnormality. In our two patients? the main finding was osteopenia with no disease specific features.

One possibility for the basic defect behind the $\vec{\oplus}$ osteoporosis-pseudoglioma syndrome is an altera- $-\infty$ tion in the biosynthetic events of type I collagen. Sn $^{\circ}$ this study neither sensitive protein chemical tech ques nor well established assays of the collagen biosynthetic enzymes were able to show any majöo abnormalities in cultured skin fibroblasts. However, $\frac{\mathrm{Q}}{8}$ these negative findings do not exclude the possibilityo of an underlying defect in collagen metabolism. The $\overrightarrow{\overrightarrow{0}}$ situation is somewhat analogous to osteogenesis 3 imperfecta, where the primary defect is likely to be? in type I collagen, but it has often been hard to? prove this with protein chemical techniques. Now that linkage studies using polymorphic markers ofo the $\alpha 1$ (I) and $\alpha 2$ (I) genes have become available, ito has been possible to show that a mutation in these. type I collagen coding genes seems to be responsibleô for the primary defect in almost all families suffering from osteogenesis imperfecta. ${ }^{14}$ Linkage studies using polymorphic markers of the structural genes coding connective tissue components might beㅡ. informative in searching for the mutated genen causing the osteoporosis-pseudoglioma syndrome.

\section{References}

1 Neuhäuser G, Kaveggia EG, Opitz JM. Autosomal recessive syndrome of pseudogliomatous blindness, osteoporosis and mil\&్ mental retardation. Clin Genet 1976;9:324-32.

${ }^{2}$ Frontali M, Stomeo C, Dallapiccola B. Osteoporosis pseudoglioma syndrome: report of three affected sibs and an overview. Am J Med Genet 1985:22:35-47.

${ }^{3}$ Beighton P. Winship I, Behari D. The ocular form of ostco genesis imperfecta: a new autosomal recessive syndrome. Clin Genet 1985;28:69-75. 
4 Brude E, Stöss H. Ostcoporosis-pseudoglioma syndromeelectron microscopic findings in the iliac crest biopsy and the differentiation to osteogenesis imperfecta. 7th International Congress of Human Genetics, Berlin, September 1986:259-60.

s Hoikka V. Arnala I. Histomorphometric normal values of the iliac crest cancellous bonc in a Finnish autopsy series. Ann Clin Res 1981;13:383-6.

${ }^{6}$ Peltonen L, Palotie A, Myllylä R, Krieg T, Oikarinen A. Collagen biosynthesis in systemic scleroderma: regulation of posttranslational modifications and synthesis of procollagen in cultured fibroblasts. J Invest Dermatol 1985;84:14-8.

${ }^{7}$ Kivirikko KI, Myllylä R. Post-translational enzymes in the biosynthesis of collagen: intracellular enzymes. In: Cunningham LW, Fredriksen DW, eds. Methods in enzymology. Vol 82. Structural and contractile proteins. Part A. New York: Academic Press, 1982:245-304.

${ }^{8}$ Juva K, Prockop DJ. Modified procedure for the assay of $\mathrm{H}^{3}$ - or $\mathrm{C}^{\mathrm{l} 4}$-labelled hydroxyproline. Anal Biochem 1966;15: 77-83.

${ }^{9}$ Deak SB, Nicholls A. Pope FM, Prockop DJ. The molecular defect in a nonlethal variant of osteogenesis imperfecta.
Synthesis of pro $\alpha 2(\mathrm{I})$ chains which are not incorporated into trimers of type I procollagen. J Biol Chem 1983;258:15192-7.

10 Laemmli UK. Cleavage of structural proteins during the assembly of the head of bacteriophage T4. Nature 1970;226: 680-5.

11 Neuhäuser G. Osteoporosis-pseudoglioma syndrome. In: Bergsma D, ed. Birth defects compendium. 2nd ed. New York: Alan R Liss, 1979:842.

12 McKusick VA. Heritable disorders of connective tissue. 4th ed. St Louis: CV Mosby, 1972:433-5.

13 Bianchine JW, Murdoch JL. Juvenile osteoporosis (?) in a boy with bilateral enucleation of the eyes for pseudoglioma. In: Bergsma D, ed. Skeletal dysplasias. New York: Alan R Liss, 1969:225-6.

14 Sykes B, Wordsworth P, Ogilvie D, Andersson J, Jones N Osteogenesis imperfecta is linked to both type I collagen structural genes. Lancet 1986;ii:69-72.

Correspondence and requests for reprints to $\mathrm{Dr}$ Hannu Somer, Department of Neurology, University of Helsinki, 00290 Helsinki 29, Finland. 